\title{
Colour Discrimination in Pseudophakia
}

\author{
R. A. HARPER, C. M. KIRKNESS and B. JAY \\ London
}

\begin{abstract}
Summary
A study was undertaken to examine the colour discrimination of fifty pseudophakic patients and to compare results with fifty age matched normal observers. Using the Farnsworth-Munsell 100-Hue test and Desaturated panel D15, performance does not differ significantly from the age matched normals, although a theoretically superior colour discriminative ability might be expected in pseudophakia. A slight trend for increasing error scores with advancing age in pseudophakia lends some support to the importance of neural factors in the ageing of colour discrimination. Several other factors influencing colour vision in pseudophakia are discussed.
\end{abstract}

Recent evidence has suggested that chronic low dosage exposure to ultra-violet (UV) radiation is potentially harmful to the ageing retina and that blue light exposure is an important factor in certain types of retinal injury. It seems likely that damage to the retina is cumulative and that quite low levels of blue light can damage the retina. ${ }^{1}$ From the age of about 50 years and above, selective absorption of short wavelength radiation by the crystalline lens effectively filters out UV radiation. The senile decrease in colour discrimination has been attributed, at least in part, to these lens changes.

Removal of the crystalline lens exposes the retina to near UV and short wavelength visible radiation. This has resulted in increasing concern about aphakic and pseudophakic eyes, since patients may live long enough to develop retinal photodamage. Polymethylmethacrylate (PMMA) intraocular lenses (IOL) absorb light maximally below $285 \mathrm{~nm}$ whilst the spectral transmittance of the normal crystalline lens decreases rapidly below $450 \mathrm{~nm}$. Many presently used IOLs are therefore made of UV absorbing PMMA materials.
Changes in colour discrimination with age have been well documented, although to date there have been only a few reports on colour vision in pseudophakic patients. Approximately $95 \%$ of patients with senile type cataracts undergoing extraction at Moorfields Eye Hospital receive IOLs, yet no normative data exists for their colour vision, which cannot be assumed to be the same as in age matched normals. Spectral sensitivity measurements of observers with clear PMMA IOLs demonstrates that they are more sensitive to short wavelength visible light than normal phakic observers of the same age. ${ }^{2}$ It is therefore possible to expect chromatic discrimination at the blue end of the spectrum to be better than in age matched normals, especially in view of the increased retinal illumination in pseudophakia. In the normal ageing phakic eye the retinal illumination will be less for a given source of light because of senile miosis, and the decreasing transmittance of the ocular media. Contrast is further reduced by the increasing fluorescence properties of the cornea and crystalline lens. It is, therefore, of some clinical as well as theoretical interest to

Correspondence to: Mr. C. M. Kirkness FRCS, Department of Clinical Ophthalmology, Institute of Ophthalmology, Moorfields Eye Hospital, City Road, London EC1V 2PD.

Presented at the Annual Meeting of the Ophthalmological Society of the United Kingdom, April, 1988. 
examine the colour discrimination of patients with IOLs and to compare performance with age matched normals.

Table I demonstrates the variability of the Farnsworth-Munsell 100-Hue normative data (for older observers) previously reported in the literature. Differences are likely to be mainly due to the illumination levels and to methodological approaches. ${ }^{7}$ Differences in age ranges, sample sizes, and criteria for normality may also be factors. Hence the importance of establishing normal data for one's own testing procedures.

\section{Patient Selection and Methods}

Fifty patients undergoing routine extracapsular cataract extraction with posterior chamber lens implantation were included in the study. Patients were chosen at random from the clinics at Moorfields Eye Hospital provided they satisfied the criteria for inclusion listed:
(1) Over 50 years of age;

(2) corrected visual acuity of $6 / 9$ or better;

(3) no other ocular disease or abnormality;

(4) examination between 3 and 6 months post-operatively.

Intraocular lenses used were the Coburn 71/ 72 UV or Rayner $850 \mathrm{U}$. Any general or ocular medication being taken by the patient at the time of examination was recorded. No attempt was made to influence the size of the pupil.

A second group of fifty age matched normals were examined from private optometric practice, under the same testing conditions. All normal observers had at least $6 / 9$ visual acuity and no ocular abnormalities. Observers were first screened for congenital colour vision deficiencies with Ishihara pseudo-isochromatic plates ${ }^{8}$ (38 plate edition, Ishihara 1985). Only observers with two or less errors on plates 2-16 were included, giving a $99 \%$ probability of normality. ${ }^{9}$

Table I Published normative data for FM-100 Hue error scores.

\begin{tabular}{|c|c|c|c|c|c|}
\hline Source & Mean & $S D$ & $\begin{array}{c}\text { Age range } \\
\text { (years) }\end{array}$ & $N$ & $\begin{array}{l}\text { Illumination } \\
\quad(l u x)\end{array}$ \\
\hline Verriest ${ }^{3}$ & $\begin{array}{l}95.4 \mathrm{M} \\
91.1 \mathrm{~F}\end{array}$ & 1 & $60-64$ & $\begin{array}{l}14 \\
15\end{array}$ & 100 \\
\hline Aspinall $^{4^{*}}$ & $\begin{array}{l}9.43 \\
9.61\end{array}$ & $\begin{array}{l}2.33 \\
2.05\end{array}$ & $>50$ & 1 & 1 \\
\hline Pinkers 5 & $\begin{array}{l}103.2 \\
111.7\end{array}$ & I & $\begin{array}{l}50-59 \\
60-69\end{array}$ & $\begin{array}{l}52 \\
18\end{array}$ & 1750 \\
\hline Verriest $^{6^{*}}$ & $\begin{array}{l}10.36 \\
10.22\end{array}$ & $\begin{array}{l}2.43 \\
1.99\end{array}$ & $50-59$ & 30 & 200 \\
\hline & $\begin{array}{l}10.93 \\
11.11\end{array}$ & $\begin{array}{l}2.59 \\
2.76\end{array}$ & $60-69$ & 28 & \\
\hline & $\begin{array}{l}13.45 \\
13.30\end{array}$ & $\begin{array}{l}2.04 \\
2.18\end{array}$ & $70-80$ & 27 & \\
\hline Reeves $^{7 *}$ & $\begin{array}{l}8.62 \\
8.62\end{array}$ & $\begin{array}{l}2.98 \\
3.06\end{array}$ & $>61$ & 24 & 750 \\
\hline
\end{tabular}

${ }^{*}$ Represents transformed data (see methods)

$\mathrm{SD}=$ Standard deviation

$\mathrm{N}=$ Number

$\mathrm{M}=$ Male

$\mathrm{F}=$ Female

Where two means are present, the data for $\mathrm{R}$ and $\mathrm{L}$ eyes are included. 
Tests used were the Farnsworth-Munsell 100-Hue and Desaturated panel D15 of Lanthony ${ }^{10}$ (chroma 2, value 8). With the appropriate near corection, both tests were administered monocularly in a colour vision test cabinet. CIE standard illuminant $\mathrm{D}$ was approximated by a $20 \mathrm{~W}$ Thorn Northlight fluorescent tube giving a level of 750 lux at the test plane. Similar instructions were given to all patients who were allowed as long as necessary to complete the tasks. All the tests in this study were performed by one experimenter in order that results should not be affected by other variables. A computer program written in Basic ${ }^{11}$ and run on an HP85 computer calculated the individual total error scores (TES) for the FM 100-Hue test and produced a composite polar diagram for the 50 pseudophakes. The results were plotted using the methods proposed by Kinnear. ${ }^{12}$

The D15 was also analysed quantitatively by the method proposed by Bowman. ${ }^{13,14}$. The method produces a total colour differ-

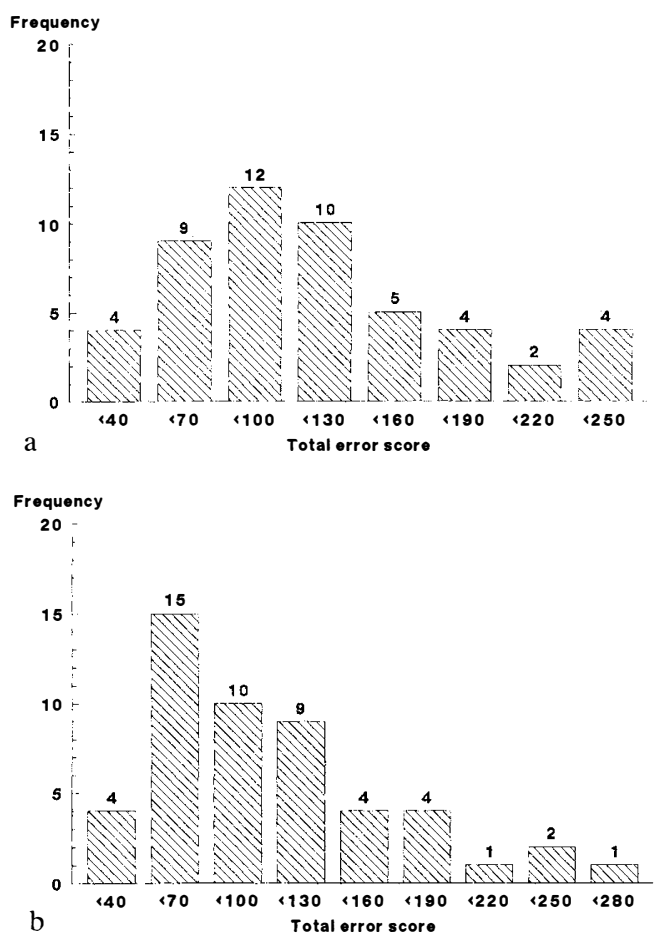

Fig. 1. The distributions of FM-100 Hue total error scores (raw data) are positively skewed for, (a) Pseudophakes, and (b) Normal observers. ence score (TCDS) from calculation of the sum of colour differences of the caps placed adjacent to one another by the patient. The TCDS is minimum for a perfect arrangement of caps since the smallest colour difference occurs between normally adjacent caps. The CIE $1976\left(\mathrm{~L}^{*} \mathrm{a}^{*} \mathrm{~b}^{*}\right)$ colour difference formula was used to calculate the colour differences between D15 caps. The tristimulus values of the illuminant were calculated from the chromaticity co-ordinates of D6500 (i.e. $\mathrm{x}=0.315, \mathrm{y}=0.329) .{ }^{15} \mathrm{~A}$ modified form of Bowman's program was written in Basic and run on an Amstrad PC which allowed rapid calculation of the TCDS.

\section{Results}

FM 100-Hue test:

It will be noted that a more nearly normal distribution of total error scores is obtained by application of a square root transformation to the raw data (Figs 1 and 2), as suggested by Kinnear ${ }^{12}$ and Aspinall. ${ }^{4}$

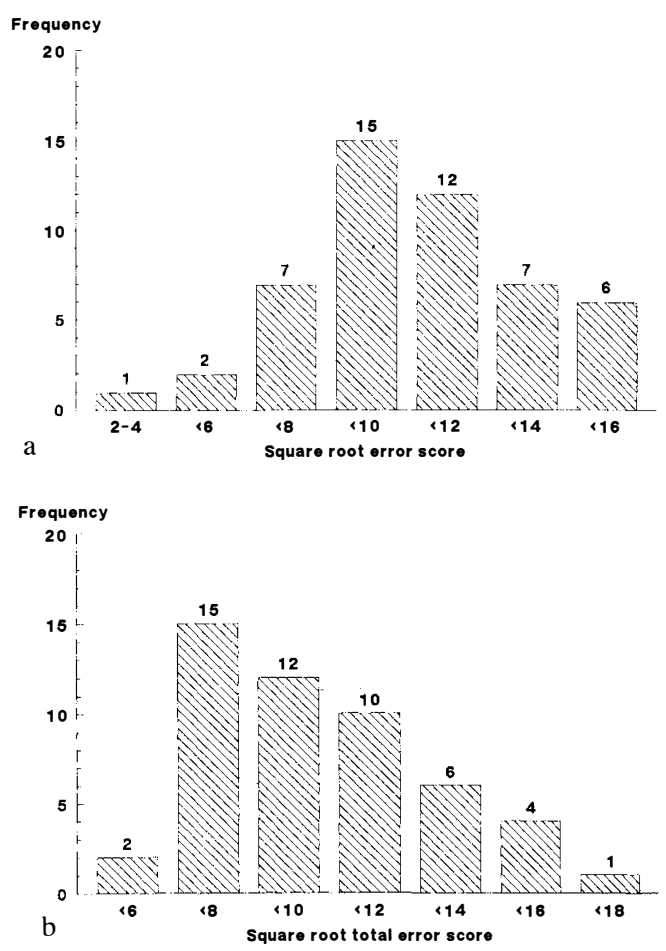

Fig. 2. Distributions of FM-100 Hue total error scores (transformed data). The square root transformation reduces the skewness for, (a) Pseudophakes, and (b) Normal observers. 
According to Kinnear the skewness of the raw data is due to the nature of the measuring scale. It will be noted that the transformed TES data is itself slightly skewed, but it does provide a better approximation to the normal distribution.

Table II summarises the results for both groups and shows the square root transformation on the raw data. Clearly the skewness value is reduced for the square root transformation, making the data more suitable for statistical evaluation.

The age range was 50-84 years for the pseudophakic group (mean age $=67.7$, $\mathrm{SD}=8.8$ ) and $50-88$ years for the normal observers (mean age $=65.8, \mathrm{SD}=8.5$ ).

A two-tailed t-test shows that there is no significant difference between the mean transformed TES of the groups.

The composite polar diagram for 50 pseudophakes is shown in Figure 3. Note that there is no well defined axis, confusions being equally well distributed about the colour circle.

\section{Lanthony's desaturated D15:}

The results of the D15 for both groups are shown in Table III. Most confusions tended to occur along the more horizontal blue-yellow axes, (1 with cap 5 and 9/10/11 with cap
15 being the most frequent cap misplacements.)

The TCDS for a perfect arrangement of caps $=57.6$. The mean TCDS for the pseudophakic group is $81.6(\mathrm{SD}=17.4)$ and for the normal group the mean $=77.9$ $(\mathrm{SD}=18.2)$. A score of approximately 80 is equivalent to either one major cap misplace-

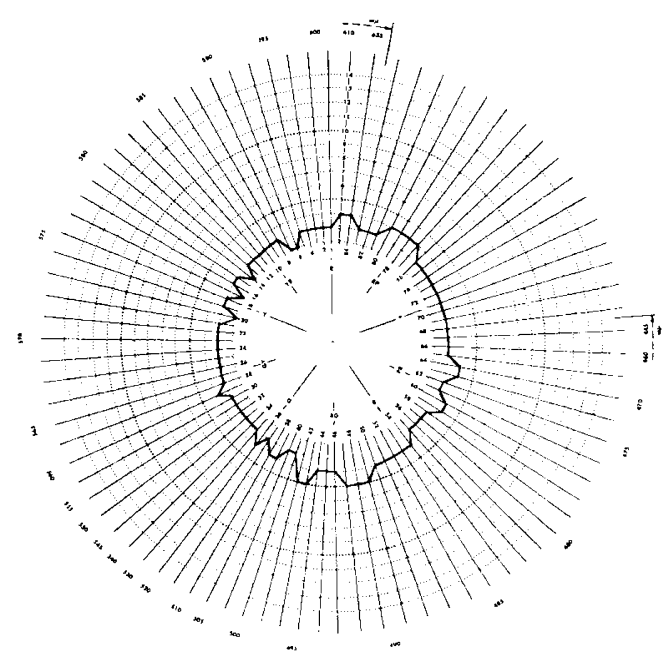

Fig. 3. Composite FM-100 Hue test polar diagram for the pseudophakic group. The total error score is moderate, and there is no well defined axis of confusion.

Table II Transformation of FM 100-Hue error scores

\begin{tabular}{lcccc}
\hline & \multicolumn{2}{c}{ Pseudophakes } & \multicolumn{2}{c}{ Normals } \\
& Raw data & Square root & Raw data & Square root \\
\hline Mean & & & & \\
SD & 109.92 & 10.09 & 99.20 & 9.55 \\
Maximum & 59.21 & 2.86 & 58.46 & 2.83 \\
Minimum & 248.00 & 15.74 & 256.00 & 16.00 \\
Kurtosis & 12.00 & 3.46 & 28.00 & 5.29 \\
Skewness & -0.38 & -0.40 & -0.03 & -0.76 \\
& 0.67 & 0.04 & 0.90 & 0.47 \\
\hline
\end{tabular}

Table III Summary of the desaturated panel D15 results

\begin{tabular}{lcccc}
\hline & \multicolumn{2}{c}{ Pseudophakes } & \multicolumn{2}{c}{ Normals } \\
\hline Defect Type: & $\%$ & Mean TCDS & $\%$ & Mean TCDS \\
Blue-Yellow & 54 & 87.3 & 42 & 85.1 \\
Mixed defect & 18 & 96.3 & 10 & 107.5 \\
Minor errors & 10 & 68.4 & 40 & 66.9 \\
Correct & 18 & 57.6 & 8 & 57.6 \\
\hline
\end{tabular}

Results for the D15 are classified qualitatively according to defect type, and quantitatively by the TCDS. 
ment or to several minor errors. Again there is no significant difference between the two sample means.

Figure 4 shows individual pseudophakic FM 100-Hue and the corresponding D15 plots, demonstrating the overall variability of results, with good, moderate and poor hue discrimination.

\section{Discussion}

Previous reports on colour perception in pseudophakia have indicated differences between aphakic and pseudophakic eyes. Jay et $a l^{16}$ using a series of 30 aphakes and 30 pseudophakes (with Rayner-Pearce posterior chamber lenses) examined colour perception with the FM-100 Hue test and the PickfordNicholson anomaloscope. Differences were attributed to the different spectral characteristics of IOLs and the aphakic spectacle correction, with pseudophakes having significantly increased error scores when compared with aphakes and normals.

That study used observers whose visual acuity ranged from $6 / 6$ to $6 / 18$; however, the $100-$ Hue test results can be significantly affected by the acuity level. ${ }^{17}$ Marre $^{18}$ also used several subjects with lower visual acuity when examining 6 aphakes, 6 pseudophakes with iris-clip IOLs and 11 with posterior chamber IOLs. Patients with posterior chamber IOLs performed better than the other two groups.

The present results of the FM-100 Hue test and Desaturated D15 (Table III) indicate a blue-yellow colour defect in approximately $50 \%$ of pseudophakic patients tested. However, there is much variability in these results.

There are several possible factors influencing colour vision in pseudophakia:

\section{(1) Intraocular lens spectral transmittance characteristics}

Aarnisalo ${ }^{19}$ has examined the colour discrimination of normal observers using various Schott filters with sharp wavelength cutoff. Filters with $50 \%$ transmittance at $438 \mathrm{~nm}$ and below had no significant effects on the FM 100-Hue error scores. The transmission of the IOLs used in this study is maximum only above $450 \mathrm{~nm}$, falling to $15 \%$ at $400 \mathrm{~nm}$.
It is unlikely, therefore that the spectral transmission properties of the UV absorbing IOLs have any significant effect on the colour discrimination of pseudophakes.

\section{(2)Post-operative effects}

Marre ${ }^{18}$ considered post-operative effects to be a factor in an acquired blue-yellow defect. It is difficult to assess independently or to quantify the effect on colour discrimination that these factors may have (e.g. posterior capsule haze, cystoid macular oedema etc.). There is some evidence that the incidence of cystoid macular oedema post-operatively is significantly lower in patients receiving UV absorbing IOLs compared with patients receiving clear PMMA IOLs, ${ }^{20}$ although Marshall $^{21}$ has suggested that filtration of the operating microscope lamp is probably a more important factor. The selection criteria used in this study will have minimised the effects of post-operative changes on colour discrimination. Mild photochemical retinal damage may not be visible ophthalmoscopically, and may not reduce visual acuity, but if present may affect colour vision.

\section{(3) Test bias}

Care must be taken with the interpretation of acquired blue-yellow defects as the tests used in this study have an intrinsic bias towards giving tritan-like results. Examination of the chromaticities of the 100 Hue caps shows that the caps between positions $80-8$ and $32-52$ are closer together making the test more difficult in those regions. Verriest ${ }^{3}$ stated that attention must therefore be given to the total error score before falsely claiming a pathological tritan deficiency. In this study, results show no significant difference in error score between pseudophakic patients and normals observers.

\section{(4) Ageing factors}

It is now well recognised that colour discrimination declines with advancing age in normals. The senile changes in colour perception were thought to be mainly due to the yellowing of the crystalline lens, senile miosis and the not infrequent occurrence of senile macular degeneration. ${ }^{3}$ Selective absorption of the short wavelength end of the visible spectrum 


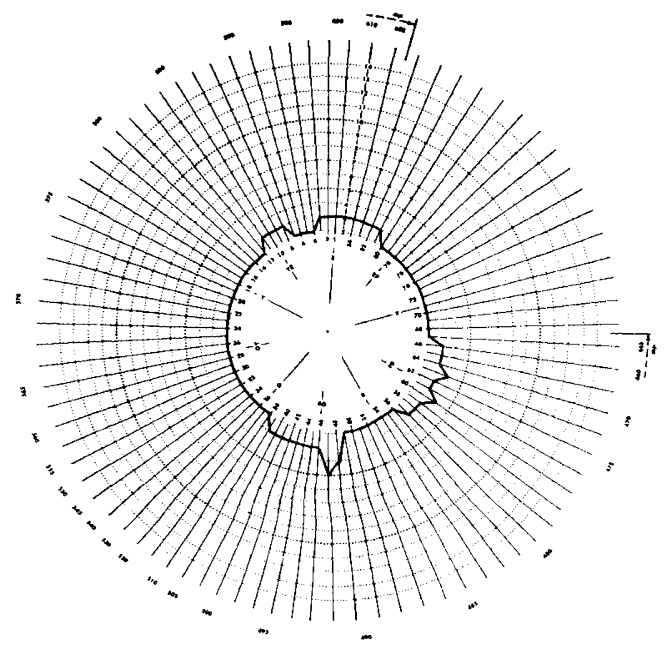

a
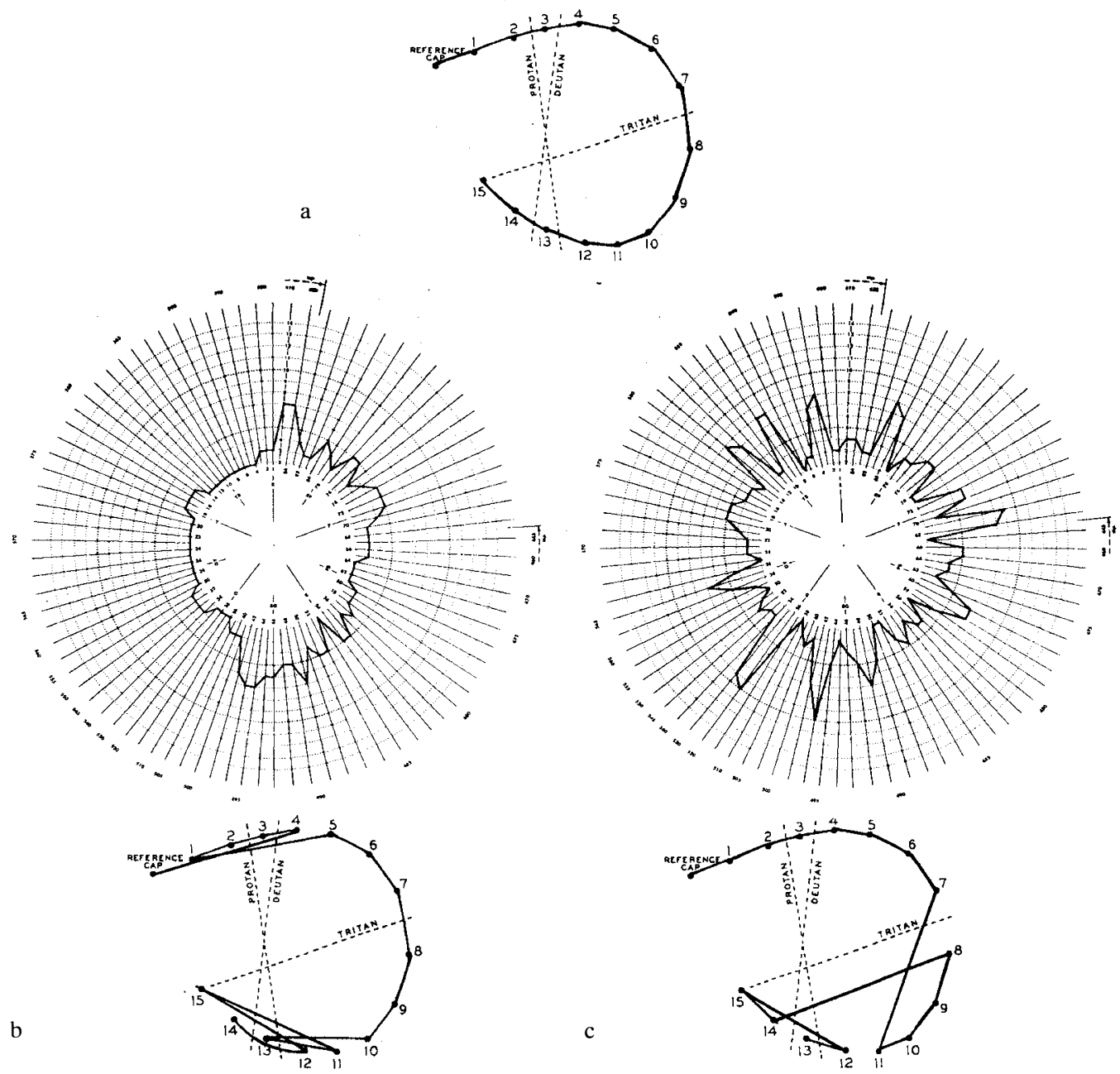

Fig. 4. Individual pseudophakic FM-100 Hue test plots with the corresponding D15 plots. (a) Showing good overall hue discrimination with a low total error score. (b) Showing a tritan axis of confusion with a moderate total error score. (c) Showing poor overall hue discrimination with a high error score, and no well defined axis of confusion. 
causes a tritan-like colour vision defect on many of the clinically used colour vision tests.

This study also confirms the trend for the declining colour discrimination of normal observers with advancing age, in spite of the truncated age range being studied. Figure 5a is a scatter plot of the transformed TES versus age. The Pearson product moment correlation coefficient, $\mathrm{r}=0.51(\mathrm{P}<0.0001)$. For the desaturated D15 r $=0.24(\mathrm{P}<0.08)$.

$\mathrm{Jay}^{16}$ noted a deterioration in colour discrimination in pseudophakia and aphakia with advancing age. Cunin-Malejac ${ }^{22}$ used metameric matches on a group of 36 pseudophakes and noticed decreased chromatic sensitivity in the short wavelength end of the spectrum especially above the age of 65 years. This study also noted a slight tendency for worse performance on clinical col-
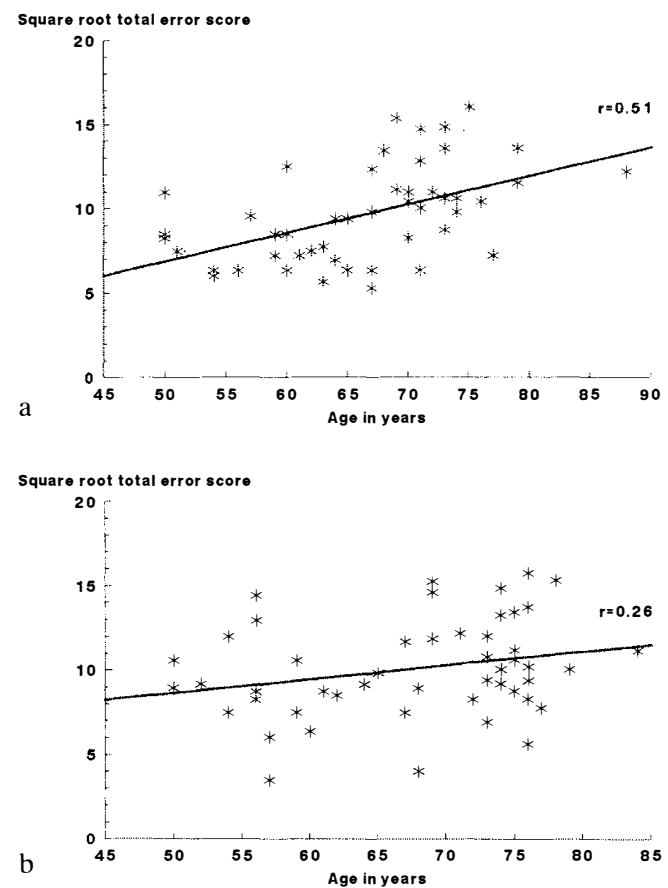

Fig. 5. Scatter plots of the transformed FM-100 Hue total error scores versus age. (a) Normal observers-there is a trend for increasing error score with advancing age. (b) Pseudophakes-there is a small trend for increased errors with age, al though it is likely that the trend would become more significant if the age range had been extended below 50 years. our vision tests with increasing age. Fig. $5 \mathrm{~b}$ is a scatter plot of the transformed TES versus age for the pseudophakic group. Although there is much variability, there is a small positive trend for increasing error scores with advancing age, $r=0.26(\mathrm{P}<0.07)$. For the $\mathrm{D} 15, \mathrm{r}=0.28(\mathrm{P}<0.05)$.

Therefore one has to consider age as a factor in pseudophakic colour discrimination. Although there is a progressive rise in light absorption of the lens ${ }^{23}$ and also the cornea ${ }^{24}$ with age, in a recent report on colour vision and age, Weale ${ }^{25}$ concluded that the senescence of chromatic discrimination is more likely to be due to neural mechanisms rather than to the filtering characteristics of the preretinal media. This would be consistent with some dependence of colour vision test performance on age in pseudophakes. Indeed, other changes in visual performance with age, such as contrast sensitivity, have been attributed to neural change, with the decrease in retinal illumination being a contributing factor. ${ }^{26,27}$ Visual acuity has also been shown to decline with advancing age in pseudophakia. ${ }^{28}$

In conclusion, it is clear that there is no significant difference in colour discrimination between pseudophakes and normals for both the FM-100 Hue test and the desaturated D15, although ageing effects and post-operative changes are considered to be factors influencing pseudophakic colour vision.

The authors would like to thank Dr. W. D Thompson and Mrs. J. Birch of The City University for the computer programs, and also M. B. Bellmore Ltd. This study was supported by Pharmacia Ophthalmics.

\section{References}

${ }^{1}$ Kirkness CM and Weale RA: Does light pose a hazard to the macula in aphakia? Trans Ophthalmol Soc UK 1985, 104: 699-700.

2 Werner JS and Hardenberg E: Spectral sensitivity of the pseudophakic eye. Arch Opthalmol 1983, 101: 758-60.

${ }^{3}$ Verriest G: Further studies on the acquired deficiency of colour discrimination. J Opt Soc Am 1963, 53: 185-95.

${ }^{4}$ Aspinall PA: Inter-eye comparison on the 100 Hue test. Acta Ophthalmol 1974, 52: 307-15.

${ }_{5}^{5}$ Pinkers A: Colour vision and age. Ophthalmologica 1980, 181: 23-30. 
${ }^{6}$ Verriest G, Leatham J Van, Uvijls A: A new assessment of the normal ranges of the Farnsworth-Munsell 100-Hue test scores. Am J Ophthalmol 1982, 93: 635-42.

${ }^{7}$ Reeves BC, Hill AR, Aspinall PA: The clinical significance of change. Ophthal Physiol Opt 1987, 7: 441-6.

${ }^{8}$ Ishihara I: Tests for colour blindness (38 plate edition). Lewis and Co London, 1985.

${ }^{9}$ Hill AR and Aspinall PA: Pass/Fail criteria in colour vision tests and their effect on decision confidence. In Verriest $G$ ed. Docum Ophthalmol Proc Series. The Hague: Junk 1982, 33: 157-62.

${ }^{10}$ Lanthony P: The Desaturated panel D15. Doc Ophthalmol 1978, 46, 1: 185-9.

${ }^{11}$ Dain SJ and Birch J: An averaging method for the interpretation of the Farnsworth-Munsell 100--Hue test-I Congenital colour vision defects. Ophthal Physiol Opt 1987, 7: 263-80.

12 Kinnear PR: Proposals for scoring and assessing the 100-Hue test. Vision Res 1970, 10: 42333.

${ }^{13}$ Bowman KJ: A method for quantitative scoring of the Farnsworth panel D15. Acta Ophthalmol 1982, 60: 907-16.

${ }^{14}$ Bowman KJ, Collins MJ, Henry CJ: The effect of age on performance on the panel D15 and desaturated D15: A quantitative evaluation. In Verriest $G$ ed. Colour vision deficiencies VII. The Hague: Dr W Junk 1984: 227-31.

15 Wyszecki G and Stiles WS: In Colour Scienceconcepts and methods, quantitative data and formulas. New York: John Wiley and Sons 1967.

${ }^{16}$ Jay JL, Gautam VB, Allan D: Colour perception in pseudophakia. Br J Ophthalmol 1982. 66: $658-62$.

${ }^{17}$ Brown L, Govan E, Block MT: The effect of reduced visual acuity upon Farnsworth-Mun- sell 100-Hue test performance. Ophthal Physiol Opt 1983, 3: 7-11.

18 Marre M, Marre E, Fulle D: Colour vision in aphakia and pseudophakia. In Verriest G ed. Colour vision deficiencies VIII. The Hague: Dr W Junk 1987: 349-55.

${ }^{19}$ Aarnisalo E: Effects of yellow filter glasses on colour discrimination of normal observers and on the illumination level. Acta Ophthalmol 1987, 65: 274-8.

${ }^{20)}$ Kraff MC, Sanders DR, Jampol LM, Leiberman $\mathrm{H} \mathrm{L}$ : Effect of an ultraviolet-filtering intraocular lens on cystoid macular edema. Ophthalmology 1985, 92: 366-8.

${ }^{21}$ Marshall J: The ageing retina: physiology or pathology. Eye 1987, 1: 282-95.

${ }^{22}$ Cunin-Malejac C, Royer J, Roth A: Colour vision in pseudophakic eyes. In Verriest $\mathrm{G}$ ed. Colour vision deficiencies VIII. The Hague: Dr W Junk 1987: 363-9.

23 Weale RA: Age and the transmittance of the human crystalline lens. J Physiol 1988, 395: $577-87$.

${ }^{24}$ Lerman S: Biophysical aspects of corneal and lenticular transparency. Curr Eye Res 1984, 3: 3-14.

${ }^{25}$ Weale RA: Colour vision and age. In Verriest G ed. Colour vision deficiencies VIII. The Hague: Dr W Junk 1987: 85-97.

${ }^{26}$ Owsley C, Gardiner T, Sekuler R, Leiberman $\mathrm{H}$ : Role of crystalline lens in the spatial vision loss of the elderly. Invest Ophthalmol Vis Sci 1985, 26: 1165-70.

27 Elliot DB: Contrast sensitivity decline with ageing: A neural or optical phenomenom? Ophthal Physiol Opt 1987, 7: 415-9.

28 Jay JL, Mammo RB, Allan D: Effect of age on visual acuity after cataract extraction. $B r J$ Ophthalmol 1987, 71: 112-5. 